\title{
Design and Development of an Automatic Controlled Planting Machine for Agriculture in Palestine
}

\author{
Mohammed Amer ${ }^{1,2, *}$, Ayman Yahya ${ }^{1}$, Ahmad Daraghmeh ${ }^{1}$, Rami Dwaikat $^{1}$, Bashir Nouri ${ }^{1}$ \\ ${ }^{1}$ Department of Mechanical and Mechatronics Engineering, Faculty of Engineering and Information Technology, An-Najah National \\ University, P.O. Box 7, 00970 Nablus, Palestine \\ ${ }^{2}$ Department of Mechanical Engineering, National Chiao Tung University, Hsinchu 300, Taiwan
}

Received April 17, 2020; Revised May 27, 2020; Accepted June 16, 2020

Copyright $\mathrm{O} 2020$ by authors, all rights reserved. Authors agree that this article remains permanently open access under the terms of the Creative Commons Attribution License 4.0 International License

\begin{abstract}
The agriculture sector occupies more than $25 \%$ of the total gross domestic products in Palestine. This provides jobs for more than $15.2 \%$ of the population in West Bank and Gaza Strip. The cultivated land is over 1.854 million dunum. However, people still using traditional ways of planting which would consume time and effort. Agriculture faces huge costs and transplant losses during planting. In this study, an automated planting machine has been introduced. This machine is a hand to the agriculture sector in Palestine. It is proposed to increase the speed and precision of planting. It is designed to do the basic cultivation steps by transmitting the transplant gently to the land. The study focused on the plants used in Palestine considering their dimensions and the distance between each two neighbor seedlings. The simulation and experimental results for the prototype showed an accurate functioning of the controlled system. Besides a precise and a smooth processing during planting, the basic planting steps were done in a satisfied way from plowing passing through planting to cover it with soil. By designing this machine, main concerns could be achieved as human needs, cost, and time saving.
\end{abstract}

Keywords Agriculture, Automatic, Farming, Planting, Planting Machine

\section{Introduction}

Agriculture is a unified system of techniques to control the growth of animals and harvesting of fruit or vegetables. Human life is mainly relying on agriculture since it is the source of food. People have no time for farming with population growth, concentrating on new technologies, and having new updated jobs. Therefore, planting wide areas becomes a need for the globe. At the same time, the planting quality should be at a high level to get low costs. This has no deal per the money-making business on the other hand.

Farming has been started 10,000 years ago [1] due to the substantial role of agriculture in human lives. Since then, people are working hard to develop the agriculture sector and transform human existence. Crops fertilizers are an option for improvement due to the high cost of organic food and the time needed to get it. Consequently, developing agriculture machines that plant huge areas becomes the first option to replace chemical substances in farming. The industrial revolution boosted the agricultural sector and gave a hand in opening specialized companies for making planting machines. The planting was via hand or through digging sticks at high efforts. The plough invention contributed to labor and time-saving. Since then, using animal power blew to human minds to save farmers' energy and time [2]. After years, the Muslim farmers worked on irrigation systems and developed many inventions on it such as dams and reservoirs. The three-field crop rotation system and the four-field crop rotation then showed where people started working on the mechanisms. The huge innovation was the tractor that showed on the surface between the $19^{\text {th }}$ and $20^{\text {th }}$ centuries. Subsequently, the competition pace begins in the agricultural industry to find innovative ways of augmenting the yields. Nowadays, the market is filled with modern farming technologies such as sowing and planting machines. These machines are so efficient and can sow most kinds of saplings. They save the number of workers and save time by planting wide areas in a very short time. In essence, planting machines save money as a major concern. Besides, planting machines are accurate in planting as planting a plant-to-plant distance. Few companies have succeeded when they worked on automatic planting machines. Any transplant structures rely not only on well-constructed machines but also on the 
seedlings that will be planted. Nowadays, the purpose is to achieve planting more than 7,000 seedlings per hour with only one or two labors [3].

Before planting machines, farms needed a lot of workers. The seedlings were planted by workers manually via drilling hole by hand or by using manual drills. Then put the sapling in the hole. Eventually, landfill by hand again. Planting in this way was tiring and did not yield much production. The planting machine used in this work works very efficiently and accurately to facilitate the process. The available research on this field is shallow. Mahesh and Priyanka have done a research on an automatic sowing and plowing machine to plant small farms [4]. Tesfaye and Hiluf designed a row planter and fertilizer applier which can plant six rows in one trip [5]. Kumar et al. proposed a seed sowing machine with a simple structure [6]. The machine can handle the weight loads of attached on the chassis as the weight of the battery, solar panel, other hardware. Patil and Mangesh developed a simple rice planter machine [7]. However, this machine can't be applied for heavy-duty stuff. Swetha and Shreeharsha designed a solar operated automatic seed sowing machine depending on the resistance movement [8]. Oscar organization developed a plating machine but it needs some farmers to run it [9]. In the case of grains, it is simple to handle them with simple machines [10]-[13]. Yevale et al. designed a seed sowing machine and purposed a model for it $[14,15]$. Vimal et al. fabricated and tested a cheap sowing machine for farming in India [16]. Girishkumar et al. fabricated a sowing matching using the basic planting procedure [17]. These machines are simple and can only plant small areas due to its simple structure [18]. Javidan and Mohammadzamani proposed a semi-automatic tomato and vegetable transplanter with a conical distributor cup $[19,20]$. Kumara and Raheman developed a vegetable transplanter for paper pot seedlings [21]. Another semi and fully automatic planter have been developed by other researchers [22-27]. Cui et al. improved rice seed tape winding units by designing an automatic system. Divate et al. proposed a Bluetooth to seed sowing machine [28]. This machine can be controlled by a smartphone. Prajakta et al. thought about using a vacuum seed sowing machine [29]. This machine is designed to process a variety of seeds to be sown via a nozzle to the land. Marode et al. proposed a machine for handling different kinds of seed [30]. Wandhare et al. [31] proposed a seed sowing fertilizer drilling machine. Gunavant et al. projected a seed planting machine to plant with a specified distance and reduce seed wasting while planting [32]. To reduce seeds wasting, Patil Nikhil et al. designed a multipurpose agriculture vehicle that could increase the productivity of the yield [33]. Abdulrahman et al. suggested a seed sowing robot to attain precise planting in a row [34].

Many researches have been done on using planting machines, however, most of them are simple. This project is not the first in this field, but it collects more than one mechanism in a unified machine. The manufacturing price is reasonable and cheap compared to similar machines in the field. Yet it works automatically without the need for workers. This machine covers many important aspects. It is environmentally friendly, no need for many workers to run the machine, fast performance, and finally, it is flexible for any developments in the future.

\section{Seedlings}

Most kinds of seedlings have nearly the same size and same weight in most hothouse plants in Palestine. An example of these plants is cucumber, squash, beans, spearmint, pepper, lettuce, tomato, eggplant, cabbage, cauliflower, thyme, and so on.

The range of seedling's mass is from $10 \mathrm{~g}$ to $25 \mathrm{~g}$, nearly for all kinds. This range is at the appreciation age of the seedlings (when the age of seedling increases, the mass increases), and if the seedlings are irrigated or not. Normally, this range is at the farm and just before planting. The size of a seedling presented in Fig. 1 (a) where A is 3 $\mathrm{cm}, \mathrm{B}$ is $4.5 \mathrm{~cm}$, and $\mathrm{C}$ is variable depending on the type of the seedling. For the previous types of seedlings, the average distance between one seedling and another is as shown in Fig. 1(b) where A is $40-50 \mathrm{~cm}$ and B is $30 \mathrm{~cm}$. These dimensions vary depending on the types of crops. Yet they are well related to the aforementioned types of seedlings. The seedling tray is made of plastic or polystyrene, and normally the tray has the dimensions as shown in Fig. 1(c) where $A=47 \mathrm{~cm}, B=70 \mathrm{~cm}$ and $C=5$ $\mathrm{cm}$. The tray contains 20 cups in length $\mathrm{B}, 13$ cups in width A, and 260 cups in total. The empty seedling tray weighs about $550 \mathrm{~g}$ and the cultivated seedling tray weighs about $3.5 \mathrm{Kg}$.

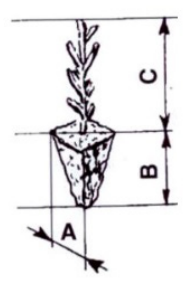

(a)

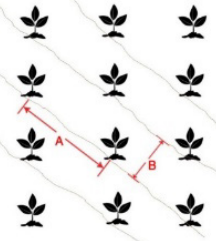

(b)

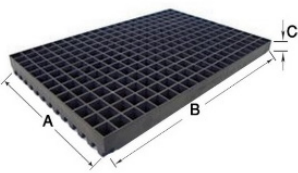

(c)
Figure 1. (a) Size of the seedling, (b) Distance between seedlings, (c) Seedling tray dimensions

\section{Control Components and Programming}

This section will show the control components that used to control the whole movement of the system, including the sensors, motors, and other components for the determination of the movement or required displacement. In this research, a position transducer encoder and a 
proximity sensor are used to transmit signals, in addition to using motors to control the movement of machine components accurately. Then, the programming procedure will be presented.

\subsection{Measurement Systems and Sensors}

To plant the seedlings precisely with a specific distance, a position transducer encoder, and a proximity sensor are used [35], [36]. The proximity sensors are position transducers in which there is no mechanical contact between the sensor and the object. Both kinds of proximity sensors are used. The inductive proximity sensor which detects only the metallic material without touching it. This sensor used as a position transducer with encoder. It can sense the location of a specific chunk within a mechanical device then process the received information. Later on, the information is converted into voltage or current signals to take action as required. This is depending on the mechanical mechanism the transducer has been applied to as shown in Fig. 2(a). This transducer is used to indicate the distance needed between the transplants by getting a signal from the metal chunk on the wheel. The sensor gives a signal "per revolution of the rotating tire" to the control unit. Arduino Uno is used to commanding the stepper motor to turn $\mathrm{ON}$ for a few seconds and let the transplant go toward the transverse pyramid. It will pass to the required spot in the land.

A capacitive proximity sensor is also used to detect the seedlings without touching them. The principle of operation of the capacitive sensor is based on the variation of a stray capacitance generated between the sensor and the detected seedling as shown in Fig. 2(b).

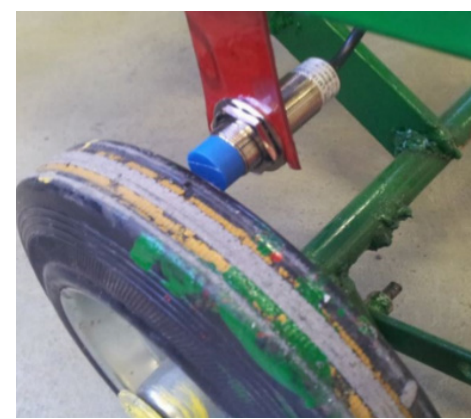

(a)

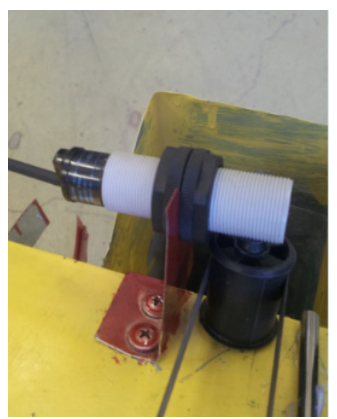

(b)
Figure 2. Proximity sensor (a) inductive (b) capacitive

The capacitive proximity sensor has a prompt response time with a high range and sensitivity that varies with sensor pad size. The capacitive proximity sensor is chosen to check if the current slot has seedling or not. The sensor gives a signal when the seedling interrupts or goes within the range of the sensor. The seedling falling driven by the belt and goes to the transverse pyramid. The same process continues until the sensor does not sense any seedling remains in the current slot in a specific time. The sensor will continue sending signals to the controller by checking the odd slot if it has seedlings or not. If the slot has seedlings, the signal will be sent to the servomotor or a pneumatic cylinder as used in this research as shown in Fig. 3(a). Yet the horizontal plate will move to replace the empty slot with a filled one.

The pneumatic cylinders (HLP Honowai) are used to replace the servo motor to move the horizontal plate when needed. The cylinder is simply working by using a pneumatic pressure provided by an air compressor installed in the machine. It is connected with a solenoid valve to make it easy to control by Arduino as shown in Fig. 3(b). The illustration in Fig. 3(c) shows the basic components of a solenoid valve circuit. The valve shown is a normally-closed and direct-acting valve.

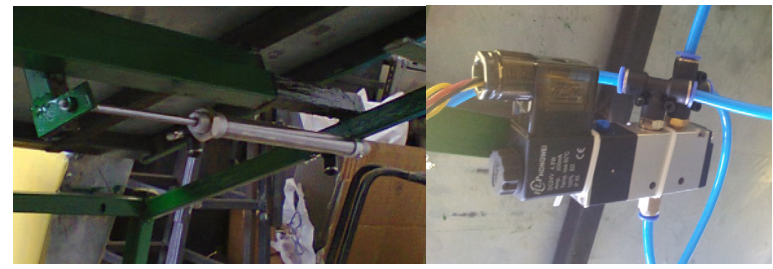

(a)

(b)

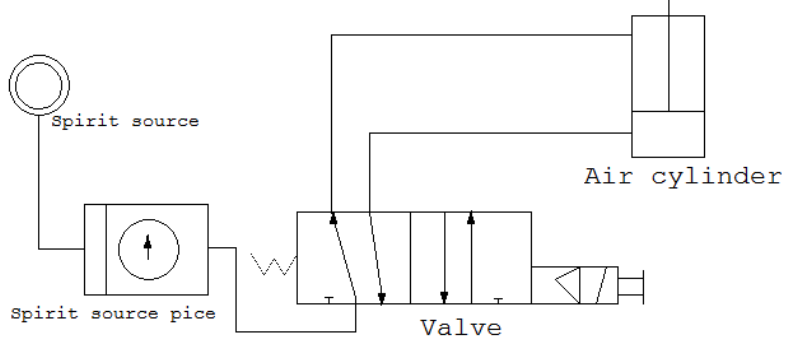

(c)

Figure 3. (a) Pneumatic cylinder, (b) Solenoid valve, (c) Pneumatic circuit

A bipolar stepper motor with 4 leads is used. The motor has a high torque and a high precision. It has a NEMA size of 17 , a sep angle of $0.9^{\circ}$, a $1.68 \mathrm{~A}$ at $2.8 \mathrm{~V}$ per phase, and a $44 \mathrm{Ncm}$ holding torque. It is mainly used as a gate to prevent falling of the transplant. It just runs when the tire rotates a complete revolution to achieve the distance between the seedlings in the same line. The sensor indicates a signal, then sends it to the stepper motor to let the transplant fall in the transverse pyramid. The other transplant will fall when the next signal generates. The servomotor could be used instead of the pneumatic cylinder since it is more accurate. The cylinders work when the capacitive proximity sensor gives a signal that indicates the first slot is empty. Thus, the microprocessor gives the cylinder a signal to turn $\mathrm{ON}$ for a few seconds till the $2^{\text {nd }}$ slot arrives at the desired place. When the capacitive proximity sensor (2) gives a signal indicating that the $2^{\text {nd }}$ slot is empty, the horizontal plate backs to the initial position. A limit switch has been used to initiate the position as shown in Fig. 4.

Figure 5 shows the proposed servomotor with a shaft 
subjected to the plate. The transmitting belts consist of two separate belts. The belts are fastening parallel to each other with suitable distance $(\mathrm{A}=3 \mathrm{~cm})$ to prevent sabotaging of the transplants. The belts have protrusions to hold the transplant and control movement permission. The belt movement is controlled by the proximity sensor and the servomotor (if used). The belt works when the encoder sensor from the tire gives an indicator of a completed full rotation. Then the stepper motor rotates until the seedling falls off. The design concept depends on taking the seedling from the end of the sloping plate, hold it between two separating belts and drop it for planting it in the ground.

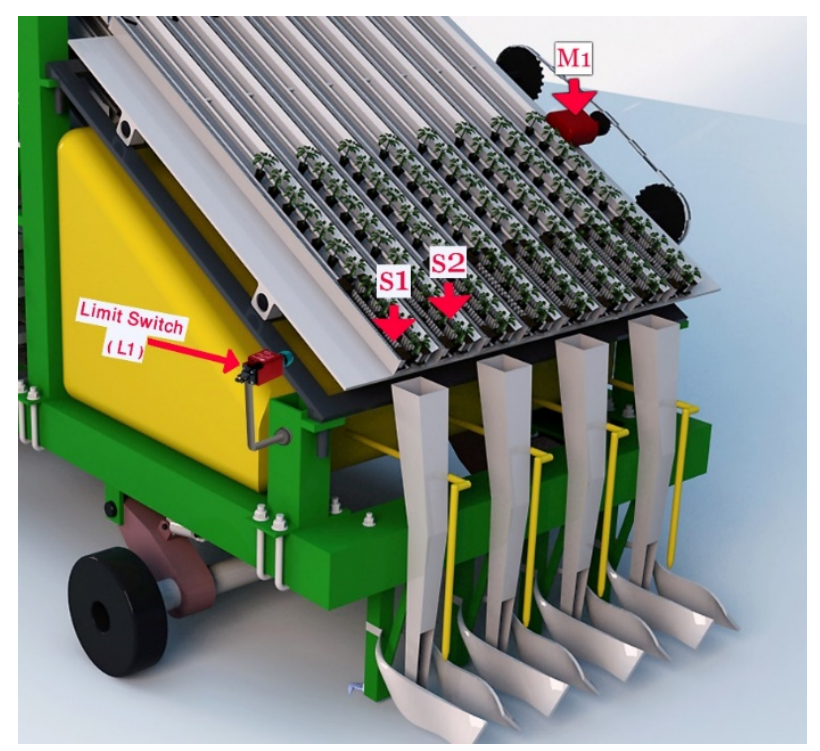

Figure 4. S1 and S2 are showing the place of proximity sensors (1) and (2), L1 is the limit switch, and M1 is the servomotor

The rotation speed of the step motor that is required to slip the transplant into the transverse pyramid is calculated as follows:

$$
N=\frac{60 \times \theta \times f}{360^{\circ}}
$$

where $N$ is the rotating speed of the step motor in rpm, $\theta$ is the step angle of step motor in ${ }^{\circ}$, and $f$ is the pulse frequency of step motor driver in $\mathrm{Hz}$.

\subsection{Programming}

Figure 5 presents the complete circuit schematic diagram for wiring the whole components of the designed machine. The components connected with the controller (Arduino Uno) are designed for two slots. The other slots are connected directly and easily to move the horizontal plate. These components are two stepper motors, servomotors (or, pneumatic cylinders), two capacitive proximity sensors, one encoder sensor, and a limit switch.

The two stepper motors are used to rotate the belts that hold the seedling on the slots. When it rotates, the seedling will fall in the transverse pyramid. The used stepper motors are bipolar type. These types have four wires connections. The steppers on the slots are connected with the Arduino to port D with PINs D (0-3 for stepper (1) and 4-7 for stepper (2)). The motors need a $12 \mathrm{~V}$ voltage supply. This voltage will be gotten easily by a driving vehicle or even a power supply. Thus, it is connected with $\mathrm{H}$-Bridge which is connected between the controller and the stepper and feed with $+5,+12$, and Ground. The solenoid valve is used to move the horizontal plate using the pneumatic cylinder via changing the airway flowing through an electric signal. The solenoid valve has three wire connections $(1,2$, and Ground). One is positive (1), another wire is negative (2), and the third wire is neglected. Since the solenoid works on $+12 \mathrm{~V}$, the relay was used to let the output $+5 \mathrm{~V}$ from Arduino deal with $12 \mathrm{~V}$. The solenoid connected to port B in the Arduino with PIN 12. The capacitive proximity sensors are connected at the end of the slots to detect the seedlings. It does not give a signal when the slot is empty. It is connected as an input to port B with PINs B1 and B2 (9, 10 of ARDUINO pins) for proximity sensors 1 and 2 , respectively. The encoder sensor is formed using an inductive proximity sensor that is connected to detect the rotation of the wheel. It is used to achieve the required planting distance between the seedlings. It is connected as an input to port B with PIN B0 (8 of ARDUINO pins). Since the sensors work with $+12 \mathrm{~V}$, the input voltage will be $12 \mathrm{~V}$. This malfunctions the Arduino which deal with 5 $\mathrm{V}$. Yet, a regulator (7805) was used to achieve $5 \mathrm{~V}$ input. Finally, a limit switch was used to detect the initial position of the horizontal plate. It is connected with PIN 11 in the Arduino as a normally closed case. 


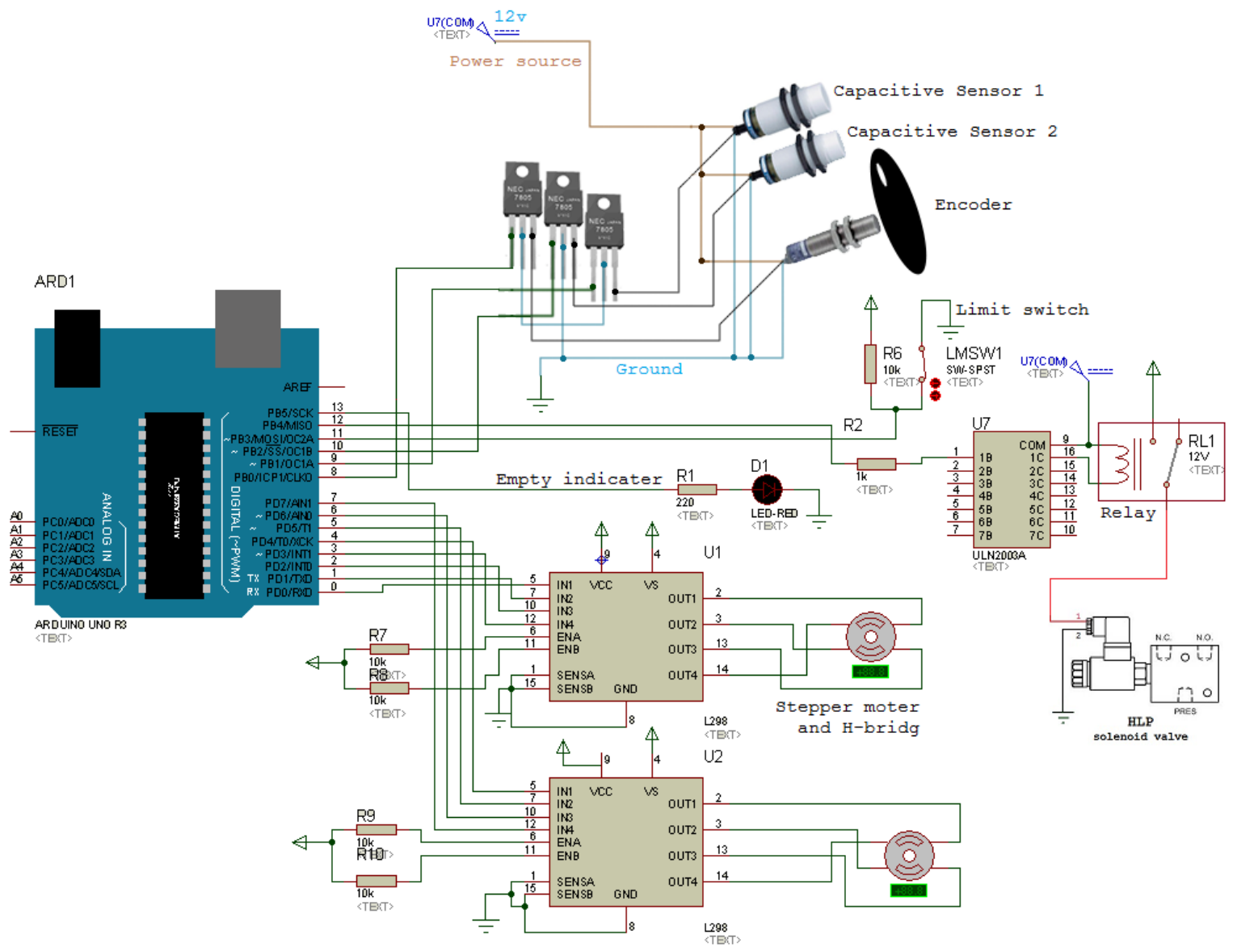

Figure 5. Circuit diagram of the machine

\section{Results and Discussion}

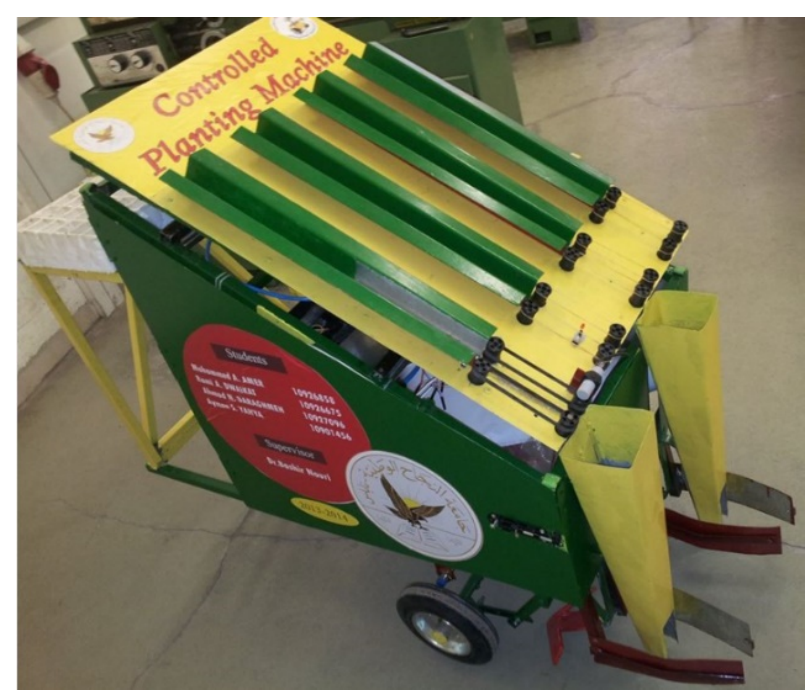

Figure 6. A prototype of the planting machine
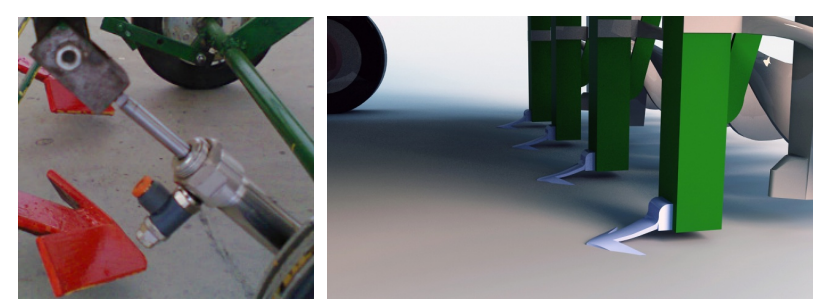

Figure 7. Plowing the land.

The results will be discussed through the principle operation of the designed machine prototype shown in Fig. 6. The first step in planting is land preparation. Preparing raw land before planting the seedlings is essential. It can make a huge difference in the seedlings' growing quality. The preparation includes removing any obstacles in the way of plants while growing and help ventilate the soil before planting. This is done by plowing the field. Also, plowing helps in getting the land as flat as possible and free the land from obstructions that facilitate machine working as depicted in Fig. 7. 
The second step-in farming is processing. The planting machine should be linked tightly with a driving vehicle as a farm tractor, a robot, or even the machine itself without the need for any vehicles. Then, the seedlings will be filled from the seedlings tray to the machine slots. The first step of the operation started by dropping the pneumatic cylinder that connected to the wheel's shaft as shown in Fig. 8.
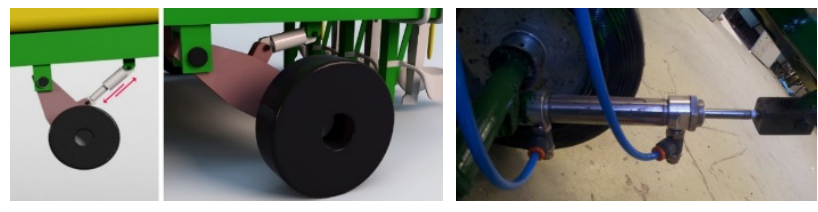

Figure 8. A hydraulic cylinder on the machine

Finally, the machine runs to plant the whole field. Even the authors did not plat a huge area since it is a prototype sample, the machine showed some effective results and smooth sowing. Note that the machine starts planting after lowering the end of the machine to get the plowers to the ground. The previous procedure will be done as follows:

(1) The shaft of the wheel will contain a circular disk as shown in Fig. 9. When the disk rotates, it gets a signal that passes through an encoder sensor to the controller. Through the controller, the sensor will determine the distance between the falling seedlings. The number of revolutions will control the number of transmitted signals. Figure 2 shows how the sensor takes signals from the wheel.

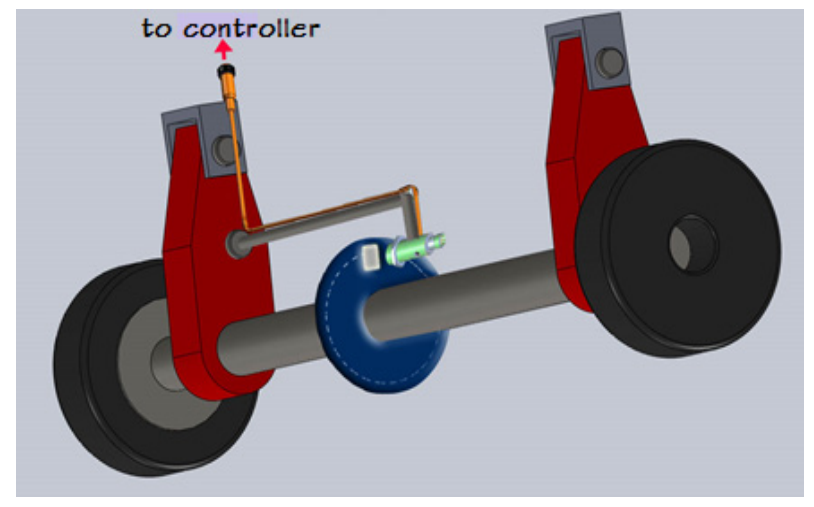

Figure 9. Circular disk on the machine's shaft

(2) The transmit seedling belt linked between stepper motors and shaft. It manages the seedlings that slip in the plate's slot by its weight. Besides manages them before slipping into the transverse pyramid by signals from proximity sensors as shown in Fig. 10.

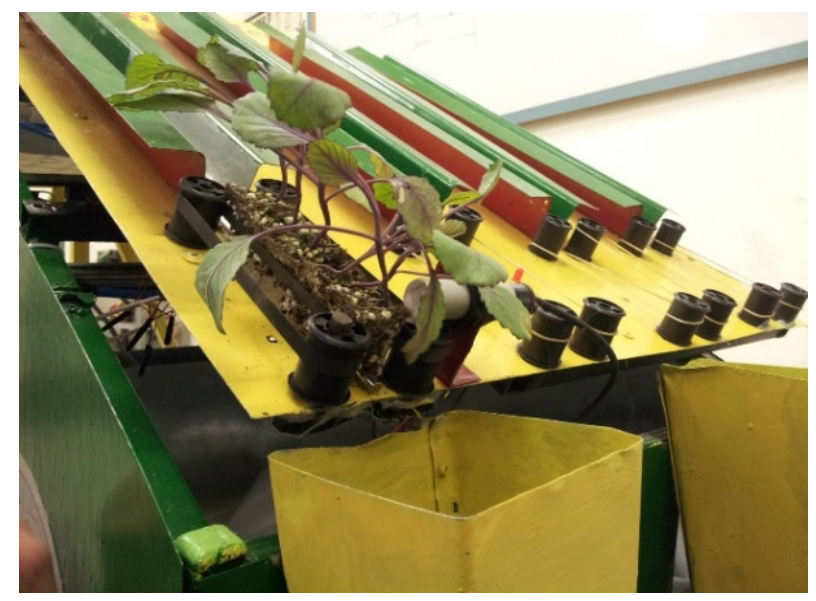

Figure 10. Circular disk on the machine's shaft

(3) Before each transverse pyramid, there is a plow leg digs a hole along the line path where seedlings will fall. The main purpose of this part is to keep the soil away from the planting path as shown in Fig. 7.

(4) After plowing, there are cones (transverse pyramids) with an oblong shape. These cones drive the seedling from the plate straight to the hole in the ground and prevent the seedling from falling diagonally as shown in Fig. 11.
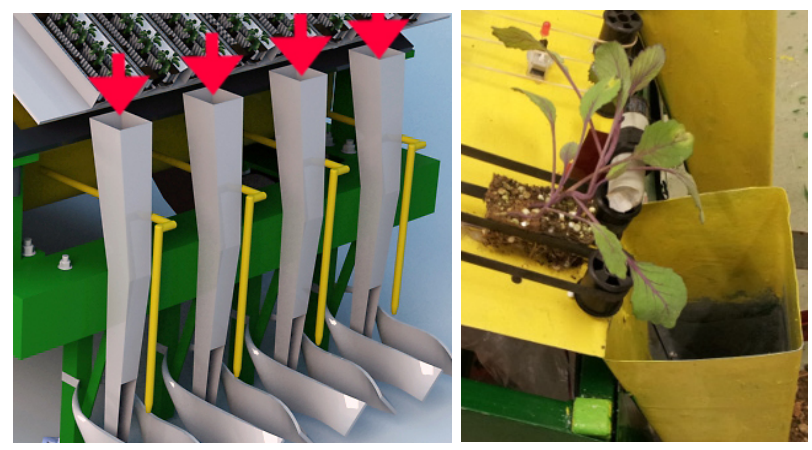

Figure 11. Seedling path to the cones

(5) Here comes the role of sanders. The sanders landfill the seedling by aggregation the soil around the seedlings as shown in Fig. 12.
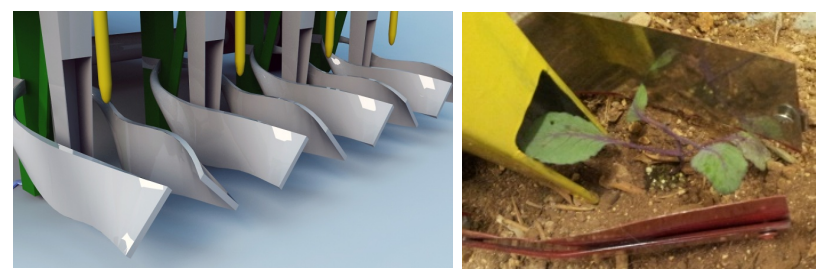

Figure 12. Machine sanders 
In general, the current porotype machine showed acceptable results in planting. All the operation steps worked smoothly as proposed. This research will be a hand for all keen researchers and farmers in the field. Moreover, the proposed porotype costs less than a thousand USD since the cost is an important issue when designing a planter [7]. Compared to the previous research papers, the planting machine does not need workers as in $[3,5,9,10$, $12,13,14,32,33]$. It can also be applied on land even as a prototype compared to other machines [37] or when they are functioned by robotic systems $[13,34]$. Note that most of the machines are for seeds and there is an obvious lack of planting transplant machines. Some of them are for special kinds of seeds or plants and most of them are just showing the main mechanism as in [28].

\section{Conclusions}

The existing research presents an automatically controlled planting machine. Investing in agriculture filed is crucial due to the importance of planting in human life. Over the years, several machines were invented in many sectors, like a tractor in traction and power, the plow in soil cultivation, spreader in fertilizing, and center pivot irrigation in irrigation and planting. The current machine is a prototype to serve this sector. It can fulfill the need and suit people in developed countries. The results showed a great functioning in which the machine can work efficiently and smoothly. The accuracy was reasonable and this machine can do the basic job in planting.

\section{Acknowledgements}

The authors would like to express deep gratitude for all the support from the An-Najah National University of Palestine.

\section{Conflict of Interest}

The authors declare that they have no conflict of interest.

\section{REFERENCES}

[1] A. Products, "http://www.agriculturalproductsindia.com/." May $25^{\text {th }}, 2020$.

[2] ThoughtCo., "https://www.thoughtco.com/history-of-agricu lture-and-farm-machinery-4074382." May $25^{\text {th }}, 2020$.

[3] IRRI, "Rice Production Manual," p. 14, 2007.

[4] M. K. Ashtankar, "Automatic Sowing and Plowing Machine," International Journal For Emerging Trends in
Engineering and Management Research, vol. Issue 1-2 $1^{\text {st }}$, January 2016.

[5] T. Gonite, "Design and Prototyping of Teff Row Planter and Fertilizer Applier," Int. J. Mech. Eng. Appl., vol. 6, no. 4, p. 91-97, 2018.

[6] A. Mathematics, "Optimising Subsidiary Crop Applications in Rotations," ijpam.eu, vol. 119, no. 14, pp. 1089-1093, 2018.

[7] D. D. Patil and M. R. Phate, "Design \& Development of Rice Planter Machine,” Imp. J. Interdisciplinary Res., vol. 2, no. 8, pp. 1241-1246, 2016.

[8] S. Swetha and G. H. Shreeharsha, "Solar Operated Automatic Seed Sowing Machine," Int. J. Adv. Agric. Sci. Technol., vol. 4, no. 1, pp. 67-71, 2015.

[9] OSCAR, "Optimising Subsidiary Crop Applications in Rotations," Final Report, March. 2016.

[10] R. Madhuri, P. P. S. Gorane, P. Ganesh, P. Shubham, and P. Nikhil, "Multipurpose seed sowing machine," International Journal of Advanced Technology in Engineering and Science (IJATES), pp. 521-529, 2016.

[11] S. D. Sambare and S. S. Belsare, "Seed Sowing Using Robotics Technology," International Journal of scientific research and management (IJSRM), vol. 3, no. 5, pp. 2889 2892, 2015.

[12] A. R. Kyada and D. B. Patel, "Design and Development of Manually Operated Seed Planter Machine," 5th Int. 26th All India Manuf. Technol. Des. Res. Conf., no. Aimtdr, pp. 590597, 2014.

[13] P. M. W. Andure, "Design and Fabrication of Manual Seed Sowing Machine with Fertilizer," Int. J. Res. Appl. Sci. Eng. Technol., vol. 6, no. 2, pp. 515-519, 2018.

[14] J.V. Yevale et al., "Design and manufacturing of seed sowing machine for agricultural field", International Journal for Scientific Research \& Development (IJSRD), 5(01): 1187-1189, 2017.

[15] H.G. Cui et al., "Design and implementation of automatic control system for rice seed tape winding units", Computer and Computing Technologies in Agriculture IV. CCTA 2010. IFIP Advances in Information and Communication Technology, Springer, Berlin, Heidelberg, vol. 344, p. 428-436, 2011.

[16] V.M. Vimal, A. Madesh, S. Karthick, A. Kannan, "Design and fabrication of multipurpose sowing machine", International Journal of Scientific Engineering and Applied Science (IJSEAS), 1(5):27-34, 2015.

[17] G.S. Girishkumar et al., "Design and fabrication of seed sowing machine", International Research Journal of Engineering and Technology (IRJET), 5(6):2185-2188, 2018.

[18] A.A. Wankhede, A.P. Rathod, A.V. Gorde, R.K. Gondane, "Design modification of advance seed sowing cum fertilizer machine", International Journal for Engineering Applications and Technology (IJFEAT), MANTHAN-15.

[19] S.M. Javidan, D. Mohammadzamani, "Design, construction and evaluation of semi- automatic vegetable transplanter with conical distributor cup", SN Applied Sciences, 1:999, 
2019.

[20] S.M. Javidan, D. MohamadZamani, "Design, development and evaluation of semi-automatic tomato transplanter", In: 10th national congress on Agr. Machinery Eng. (biosystem). Mashhad (2016).

[21] G.P. Kumara, H. Raheman, "Development of a walk-behind type hand tractor powered vegetable transplanter for paper pot seedlings", Bio. Syst. Eng., 10(2):189-197, 2011.

[22] M.A. Ladeinde, "Performance of semi-automatic tractor-mounted cassava planter", Agricultural Mechanization in Asia-Africa and Latin America, pp 27-33, 2010.

[23] A. Mahdian Soltanabadi, "Design, development and investigation of semi-automatic cabbage transplanter", In: 05th national conference on agr. machinary engineering and mechanization, Mashhad (2006).

[24] A.B. Margolin, "Development of semi-automatic transplanter", Acta-Hortic, 187:158, 1986.

[25] D.G. Mohammadzamani, "Design, construction, and evaluation of fully-automatic tomato transplanter", J. Eng. Res. Agric. Mech. Syst. , 2016.

[26] A. Patil, "Design, development and testing of hand held vegetable transplanter", Int. J. Adv. Res., 3(1):247-253, 2015.

[27] O. Taki, "Development of semi-automatic transplanter for dense planting", 15(3):67-80, 2014

[28] A. Divate et al., "Mechatronical seed sowing machine", GRD Journals-Global Research and Development Journal for Engineering, 2(5):53-57, 2017.

[29] D. Prajakta et al., "Review on design and fabrication of vaccum seed sowing machine" International Conference on Ideas, Impact and Innovation in Mechanical Engineering (ICIIIME 2017), 5(6): 887-889, 2017.

[30] R.V. Marode, G.P. Tayade, S.K. Agrawal, "Design and implementation of multi seed sowing machine", Int. J. Mech. Eng. \& Rob. Res., 2(4):422-429, 2013.

[31] M. Wandhare et al., "Seed sowing fertilizer drilling machine", International Journal of Innovative Science, Engineering \& Technology (IJISET), 3(4): 15-18, 2016.

[32] P.S. Gunavant et al., "Farm mechanization by using seed planting machine", International Advanced Research Journal in Science, Engineering and Technology (IARJSET), 4(1):75-79, 2017.

[33] V.P. Nikhil et al., "Multipurpose agriculture vehicle", International Journal of Advanced Research in Computer and Communication Engineering (IJARCCE), 7(5):14-17, 2018 .

[34] Abdulrahman, M. Koli, U. Kori, Ahmadakbar "Seed sowing robot", International Journal of Computer Science Trends and Technology (IJCST), 5(2):131-143, 2017.

[35] K. H. Beyer, “The Laboratory,” Ther. Innov. Regul. Sci., vol. 4, no. 1, p. $6,1970$.

[36] J. P. Bentley, "Principles of measurement systems," [Elektronisk resurs], 2005.
[37] K. H. Beyer, "Automatic seed sowing \& irrigation agribot using Arduino," International Journal of Pure and Applied Mathematics, vol. 119, no. 14, p. 1089-1093, 2018. 